\title{
Competency-Based Training Model for Mathematics Teachers in Virtual Platforms
}

\author{
Marco Jácome \\ Universidad de Cuenca, Ecuador
}

\begin{abstract}
We display a working model for competencies in the areas of algebra and geometry, designed for implementation through virtual platforms in teacher training. This model arises from the course "Teaching Skills in Algebra and Geometry Teachers Training" and has worked with freshmen career teachers training at the University of Cuenca, Ecuador. The eight competencies studied are divided into four skills in mathematics and four on mathematical communication proposed by Niss (2003). The model design includes: the creation of multimedia material, a video presentation of content classes, learning activities and assessment rubrics. For its implementation, we have considered alternative methodologies such as the collaborative learning groups and work through the virtual platform Moodle with a group of twelve first-year volunteer students. Currently, this model is available as an open course that also serves as a support tool in the training of mathematics teachers.
\end{abstract}

\section{Introduction}

During the 2014-2015 school year, we implemented a virtual online course with twelve first year volunteer students from the Career Training Teachers of Mathematics at the University of Cuenca in Ecuador. The course was called "Teaching Skills in Algebra and Geometry for Teachers in Training". Due to the particular popularity and success it had among the participants, the idea to validate it arose and it was decided to convert it into an open and mass course, improving the learning activities designed based on the previous results. Currently, this program is active and available to any student or teacher of the University of Cuenca who has access with a password to the Moodle platform of the institution.

The free and open courses known as Massive Online Open Course (MOOC), currently have a wide acceptance and popularity. You could even say that they are booming, mainly because they have been driven by prestigious international institutions such as the Massachusetts Institute of Technology (MIT). Also, there has been the creation of its own platforms, such as "Coursera" or "Miriada X", with great success. This popularity, along with the special opportunity offered by software and multimedia resources to create learning activities of algebra and geometry, prompted us to maintain the course and make it available to students and teachers as a support to teaching.

It is necessary to create these learning spaces because, as we showed in the study, teaching resources used in math classes and their methods have many influences on students from the pedagogical point of view training. The possibilities offered by these new tools impulse imagination, creativity, and learning, hence we want to extend the experience to make it available to more people in any modality.

\section{Objectives}

- Design and evaluate a competency model for algebra and geometry for mathematics teachers in training.

- Implement the model as open virtual courses on training with emphasis on math skills.

\section{Theoretical Review}

One of the main demands in the Ecuadorian educational system focuses on the construction of knowledge in the development of logical, critical and creative thinking, through the implementation of educational objectives based on the acquisition of competences and skills. Regarding math skills, according to official information from the Ministry of Education of Ecuador [1], teachers should ensure that students are competent to:

Think Carefully: Think, reason, analyze and argue logically, critically and creatively. Also: plan, solve problems and make decisions. 
Numerically Reason: Know and use mathematics in formulating, analyzing and solving theoretical and practical problems, as well as in the development of logical reasoning.

Use Technology Reflexively and Pragmatic: Utilize information and communication technology to search and understand the surrounding reality, solve problems, have access to the information society and express their creativity, avoiding the appropriation and misuse of information.

These competences will only be possible to develop by a teacher who possesses it and has trained as a math teacher. In addition, no mathematical knowledge enables the person for teaching [2], it is therefore essential to also develop teaching and assessment skills. These reflections and needs led us to consider this competency model and validate it with an evaluative process. It is complex to evaluate educational processes, especially in teacher training courses and furthermore complex when it is being obtained on-line [3], so to optimize performance and better validate the competency model, we created peer assessment tools aimed at measuring type headings: the math skills acquired and the level of understanding of the skills worked.

In summary, we have proposed an assessment that allows us to measure whether the training process serves a student to learn mathematics and to communicate about and with mathematics; besides generating abilities in the use of tools and mathematical language as teachers in training. A student-teacher, who appropriates these abilities, would be better able to teach.

In this regard we have validated the course using it as an evaluation axis attainment of the two competitions of Niss [4] that we also found in the Program for International Student Assessment (PISA), where the structures are in this form [5]:

A) The ability to place and answer questions about and with mathematics:

1. Think mathematically. Understand and use concepts dice: abstract concepts and generalize results.

2. Formulate and solve mathematical problems.

3. Being able to analyze and construct mathematical models in relation to other areas. Perform modeling diced contexts, mathematize situations.

4. Be able to reason mathematically. Monitor and evaluate mathematical arguments of others, understand what is and is not a demonstration, to be able to carry out informal and formal reasoning.

B) The ability to handle the tools and mathematical language:
1. Use various representations. Being able to switch from one to another.

2. Use the language of mathematical symbols and formal systems. That is, encoded symbols and formal language; translating from one language to another, trying formulas and symbolic expressions, etc.

3. Being able to communicate with and about mathematics, that is interpreting texts in different languages; write texts with different levels of accuracy, etc.

4. Use aids and tools, know your limitations and use them reflexively.

\section{Methodology}

The research design is descriptive exploratory. The methodology proposed for achieving the objectives of quantitative type was by applying questionnaires and receiving tasks, which has helped us to make assessments of the academic performance of students to teachers and their competence level in mathematics. The information was submitted for analysis using the Excel software (v2010).

To obtain the data, you work with a course based on specific topics of the courses of Algebra and Geometry in high school [6]. The course is designed on Moodle to be self-sufficient in distance mode. We put multimedia authoring into our own resources along with learning activities for production tasks [7]. We have inserted two questionnaires Moodle type performance test, income and final. The course was assembled and made available to the twelve volunteers for the study.

The standard questionnaire tests allow us to collect information to analyze the categories that emerge from the A1 and A2 sub-competencies. For its determination, we have chosen score categories based on correct, incorrect or blank responses. The tasks are divided by topics of algebra and geometry. For the competencies A3 and A4, and B1 to B4, we worked on subtopics that were shared with learning activities and then asked developing tasks where we found the level of achievement. Each week has 5 hours of work. They are enunciated below:

Task 1: Modeling using short videos with Flipped Classroom methodology. We verify the A3 competence by criteria: is able to build a valid model; is able to mathematize the situation.

Task 2: Problem-based learning for workgroups. We noted the A4 competence using the following criteria: is able to reason mathematically; is able to monitor and evaluate mathematical arguments of others; is able to carry out informal and formal reasoning. 
Task 3: Development of teaching material for the: "Do It Yourself" methodology. We worked competences B1 and B3 based on the criteria: is able to use different representations; is able to communicate with and about mathematics.

Task 4: Development of multimedia material using the "Flipped Classroom" methodology: Competencies for the analysis are the B2 and B3 according to the criteria: is able to express their mathematical ideas in formal language; translate to formal language symbolic expressions; is able to communicate accurately about math.

Task 5: To form communities for mutual aid. We verify B4 competence based on the criteria: is able to use aids and tools at your disposal; is able to use aids and tools reflectively.

To determine the level of achievement, a record of assessment criteria according to Van Hiele [8] was implemented, similarly contained in Article 9 of the "Ley Orgánica de Educación Intercultural" of Ecuador (LOEI) [9].

\section{Results}

The following shows the main results for each of the skills mentioned.

\subsection{Results compared of initial and final test. A1 and A2 subcompetences}

The tests show a significant correlation, especially in evaluating the relative performance improvement. The test results for each subtopic were:

Linear Function: It does not reach the average level of achievement, but the performance is near $42 \%$, however, this means a major advance over the boot test where we have only $25 \%$. We can say that at least ten of them are "to achieve" the A1 and A2 skills for this sub-topic, i.e. think mathematically and solve mathematical problems.

The Straight Line: It is the subtopic that best represents the advances, regarding the performance of $29 \%$ in the start-up testing. We see that on average the group is "to achieve" a $66.67 \%$ yield, five of them are on the level and only one of twelve fails. We can say that the group manages to abstract concepts and generalize the results based on mathematical models.

Inverse and Exponential Functions: We maintain the level of "not achieve" with a $42 \%$ yield, which is approximately the same as the start. We note that eight of the participants are at the level "to achieve" the competition and one of them exceeds. We do not see unanswered questions like in the initial test.
Geometric Bodies: Although the $47 \%$ remain at the level of "not achieve", we note that the averages have risen considerably from the initial level of $11 \%$. However, we have five success cases.

Areas: We see that the required subcompetencies are "not achieve". It is the sub-item for which progresses less, although it has improved from a baseline that was $17 \%$. The average is now $22 \%$.

Volumes: We get a yield of $33 \%$ which leaves us in the "not achieve" level. It is the only sub-topic in which there is a decrease in performance compared to the initial level, which was $39 \%$. We believe it could be due to the fact that it was the only sub-topic in which no task was sent by using the given time in applying the final test. In general, the subject of geometry maintains the tendency to be more complicated for students.

In the table below we compare the performance by themes:

Table 1. Comparison of the relative improvement for each subtopic

\begin{tabular}{|c|c|c|c|}
\hline Subtopics & Start & End & RI \\
\hline Linear Function & 2,50 & 4,17 & $66,7 \%$ \\
\hline The Straight Line & 2,92 & 6,67 & $128,6 \%$ \\
\hline Inverse and Exp. Functions & 4,58 & 4,60 & $0,36 \%$ \\
\hline Geometrics Bodies & 1,11 & 4,72 & $325 \%$ \\
\hline Areas & 1,43 & 2,22 & $55,56 \%$ \\
\hline Volumes & 4,05 & 3,33 & $-17,6 \%$ \\
\hline Average & 2,76 & 4,29 & $55 \%$ \\
\hline
\end{tabular}

We can see that the relative improvement is important, especially in The Straight Line and Geometrics Bodies. The Highlights start-up time test execution has diminished considerably; the average is 14 minutes compared to 19 minutes it took in the boot test.

The relative improvement for each student can be seen well in Figure 1.

We have observed a significant relative improvement. We can see the cases of the students 2 and 6, which maintain their results in the final test, a fact that is corroborated by the results of the tasks that showed red code of not delivery. We believe that if these cases have not submitted, the relative improvement would be even greater. On the other hand, it shows a notable improvement for most students, which is corroborated by the given tasks and their relative improvement. 


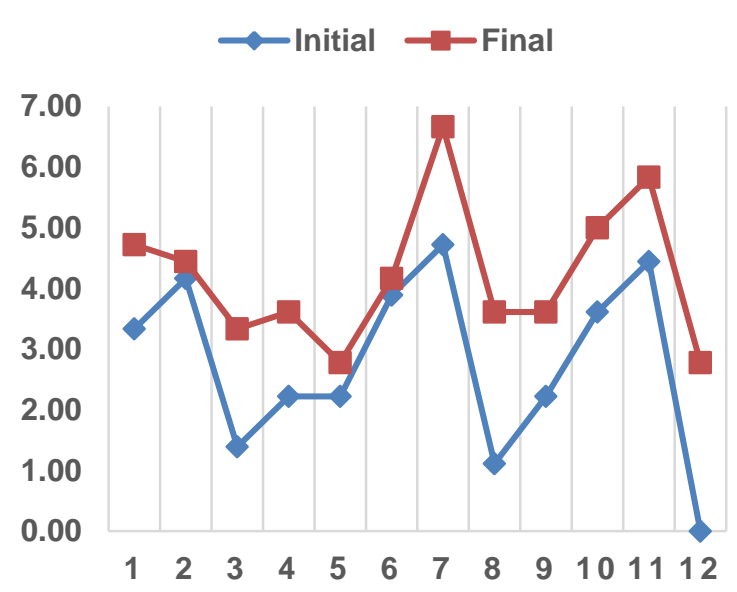

Figure 1. Comparison of the performance by student

For the analysis of significance made, we see that there is a significant improvement relative level around $55 \%$ in the intervention.

\subsection{Results A3 subcompetence}

Learning activities where tasks generated progress is observed in the development of competition A3. There is a tendency to accomplish the tasks in a good way, but five of them are not delivered and two are in very poor shape. Improve performance level regarding measures competence in proof of income as discussed in section 5.1. Students who have not given the task had 0 of qualification, but it not affects the average for the group, because only we analyzed the subcompetence with evidence of the work done. The group that hands the task is in the level "by achieve": the group is "by achieve" valid mathematical models from data and "by achieve" mathematize the proposed situations in task 1 .

\subsection{Results A4 subcompetence}

On average, the group remains at levels "to achieve" in task 2. The majority still fail to reason mathematically; have difficulty following the mathematical reasoning of the explanations and shared resources. As to express their thoughts and ideas informally the level is "to achieve", but drops dramatically when they have to formalize in writing or symbolic representations, all but two cases.

\subsection{Results $B 1$ subcompetence}

We have determined they have potential, yet still, they fail to make different representations of a logarithmic or exponential model as changes of scale, variable or generalizations of obtained models. They also have difficulty communicating. No shares outstanding about it are verified, except for the case of the student 11 that dominates task 3 .

\subsection{Results $B 2$ and $B 3$ subcompetences}

The evaluated video as a task 4 for the verification of these sub-competencies shows levels "to achieve", except by the students 3, 7 and 8 . The group does not yet formally communicate their mathematical ideas, at least not accurately and fail to translate symbolic expressions into formal language that involves the activity, including the formulas and graphics.

\subsection{Results B4 subcompetence}

We note the outstanding participation in task 5 , and we can say that it is the best activity by the group, although I must say that it was coordinated by students who were more prominent in the previous activities. They have been able to use aids and tools at their disposal to convey their ideas with short videos and "prezis", at least at an informal level. They have been able to use the aid offered in the course such as software (Poly Pro) and specialized websites (Gauss Project).

The average yield of the competencies A and B, measured by the level of the five tasks, is near $65 \%$, reaching the level achievement optimum.

\section{Conclusions}

We have achieved a 55\% improvement on competency type A1 and A2 in algebra and geometry through the intervention of six weeks for students who will be math teachers.

We have obtained an average yield of $65 \%$ in mathematics competencies type A3, A4 and B1 to B4 by this intervention.

It is feasible to implement Moodle courses with good results. This requires designing them as spaces that take into account issues such as communication, learning activities and evaluation.

It is possible to work math skills by introducing innovative methodologies like "Flipped Classroom" and "Do It Yourself" mounted in distance learning courses on virtual platforms.

Moodle is a great tool for creating online courses, especially when you want to work on tasks and evaluate activities. It is a free and available platform in almost all institutions.

Working with mathematical content for skills development is a strategy that would work in the classroom training of teachers. We see evidence of its effectiveness in virtual courses so you should also 
consider the contact sessions as a tool for teaching support.

Using Moodle retains evidence of teaching experience and serves as a portfolio with which they could improve and propose future courses.

\section{References}

[1] Ministerio de Educación de Ecuador. "Actualización y fortalecimiento curricular, área de matemática". Editorial Don Bosco. Quito 2010.

[2] Jácome, M. "Estudio de la influencia de los medios de comunicación en la formación de competencias docentes del profesor de matemáticas en Ecuador". Doctoral proyect. University of Barcelona. Spain. 2012.

[3] Bautista, G. "Didáctica universitaria de entornos virtuales de enseñanza aprendizaje". Narcea editores. Madrid. Spain. 2006.

[4] Niss, M. "The Danish KOM project and possible consequences for teacher education". IMFUFA, Roskilde University. Denmark. 2003.

[5] González, M. “Competencias básicas en educación matemática". Ediciones del Departamento de Mathematicas de la Universidad de Málaga. Spain. 2003.

[6] Ministerio de Educación de Ecuador. "Matemática 10”. Editorial Don Bosco. Quito. Ecuador. 2011.

[7] Mora, L. Rosich, N. "Las actividades matemáticas y su valor competencial”. Revista Números. Volúmen 76, págs. 69-82. Canarias. Spain. 2011

[8] A.P. Jaime y A.R. Gutiérrez. "Una propuesta de Fundamentación para la Enseñanza de la Geometría: El modelo de van Hiele, Práctica en Educación Matemática" Capítol 6, pag. 295-384. Ediciones Alfar, Sevilla. Spain. 1990.

[9] Ministerio de Educación del Ecuador. "Reglamento de la Ley Orgánica de Educación Intercultural”. Artícle 9, Decret No. 366. Quito. Ecuador. 2014. 